\title{
LA OMISIÓN PROPIA Y LA COMISIÓN POR OMISIÓN O IMPROPIA EN EL CÓDIGO ORGÁNICO INTEGRAL PENAL ${ }^{1}$
}

\author{
Alvaro Francisco Roman MarqueZ ${ }^{2}$ \\ UNIVERSIDAD CENTRAL DEL ECUADOR
}

\section{RESUMEN:}

En el presente artículo se ha realizado la construcción de la omisión, un tema que, en el Ecuador, es poco tratado y casi nunca escrito, por ese motivo vi la necesidad de escribir para aportar y que sirva de insumo a la construcción sobre esta categoría. En ese contexto, el tema resulta, sumamente interesante y complejo, por la forma como la dogmática ha discutido la omisión desde las diversas escuelas del delito, conocimiento que nos ayuda a entender el tema para poder trasladarlo al Ecuador, bajo una construcción propia. La omisión propia tiene diversa construcción que la omisión impropia. También se trató de abarcar la categoría

1 Artículo recibido el 23 de diciembre de 2019 y aprobado el 24 de enero de 2020

2 Docente de la Universidad Central del Ecuador (pre grado y maestría), de la Universidad Andina Simón Bolívar, sede Quito; de la Universidad San Gregorio, Portoviejo. (en ambas en maestría) Magister en Derecho con mención en Constitucional (UASB), Magister en Derecho Penal y Procesal Penal, (UCE). Doctorando en Derecho por la UASB. Abogado en libre ejercicio de la profesión. Correo electrónico: aroman@uce.edu.ec. 
de la posición de garante, con todas sus fuentes, tanto formales, como materiales, mixtas y de imputación objetiva, con la finalidad de poder entender la equiparación de la acción con la comisión por omisión. Lo que debemos entender son las fórmulas que se han discutido para buscar la equiparación de la acción y de la comisión por omisión.

\section{PALABRAS CLAVES:}

Garantismo, omisión propia, comisión por omisión u omisión impropia. Posición de garante. Fuentes de la comisión por omisión

\section{ABSTRACT:}

In this article, the construction of the omission has been carried out, because is an issue that in Ecuador is little treated and almost never written. For that reason, I decided to write to contribute as an input to the construction on this category. In this context, the subject is extremely interesting and complex due to the way dogmatic has discussed the omission from the various schools of crime, which helped understand the issue, in order to transfer it to Ecuador under its own construction. Self-omission is understood to have a different construction like improper omission. It also tried to cover the category of the guarantor position with all its sources, both formal, material, mixed, and objective imputation, in order to understand the equation of the action with the commission by default. What we must understand is the formulas, that have been discussed to find the equation of action and commission by default. 


\section{KEY WORDS:}

Guarantee, own omission, commission for omission or improper omission, guarantor position, sources of commission for omission

\section{SUMARIO:}

1. Ubicación de la omisión en el ordenamiento jurídico ecuatoriano;

2. La omisión;

3. El tipo objetivo en el delito de omisión impropia;

4. La existencia de la causalidad en el delito de omisión;

5. El delito de omisión impropia;

6. La posición del garante;

7. Los elementos del delito de omisión impropia; y,

8. Conclusiones. 


\section{UBICACIÓN DE LA OMISIÓN EN EL ORDENAMIENTO JURÍDICO ECUATORIANO}

Cuando el Ecuador, con la elaboración de la Constitución de 2008, se adhiere al modelo explicativo del garantismo, éste tiene dentro de su construcción axiomas garantistas ${ }^{3}$, tanto de carácter penal y procesal; los primeros son los de retribución, materialidad, lesividad y culpabilidad; los segundos son de jurisdicción, acusatorio, probatorio, contradicción y defensa.

Estos constituyen límites y son vinculantes para el poder punitivo, es decir, debemos entender que la primera función debe servir para que el poder en el ejercicio de sus competencias, se abstenga de realizar acciones, que puedan afectar los derechos; y, en la segunda, es vinculante, porque sus acciones deben fomentar la vigencia de los derechos para que los ciudadanos los puedan ejercer a plenitud, sin restricciones abusivas.

En ese sentido, el axioma de la materialidad, en primer momento, tiene relación directa con el Derecho penal, de acto o de hecho, que surgió para criticar al Derecho penal de autor, que es la construcción de perseguir a las personas por sus creencias, ideologías, por cuestiones biológicas y construcción de índole social, que constituían un peligro para la sociedad, el gobernante de turno y el grupo hegemónico. En conclusión, se castigaba por lo que eras, por tu personalidad.

Para contradecir, la modernidad construye el Derecho penal de acto, cuya principal preocupación es que la acción prohibida por la Ley penal, debe ser exteriorizada o como se sostiene es la que

3 FerRAJOLI, L. Derecho y Razón. Valencia, Editorial Trotta, 2001, p. 93. 
se debe realizar o no realizar; en consecuencia, debe tener una existencia en la realidad para que se pueda valorar con criterios objetivos, verificarse mediante la prueba o demostrarse científica y técnicamente para determinar que se trata de una acción u omisión, que se realizó la acción hacia el mundo; por tanto, para el finalismo y siguiendo el Derecho penal de acto, en los textos legales siempre debe existir una acción u omisión final.

El axioma de lesividad es cuando esa acción que se exterioriza o se realiza se encuentra prohibida u ordenada por la norma que está contenida en el texto legal del tipo penal y que se deduce lógicamente de la interpretación que se realiza; esta norma de conducta debe ser de acción u omisión y cuando se realiza, debe ser penalmente relevante, es decir, peligrosa contra el bien jurídico, ya que debe tener la capacidad de producir un resultado, con el cual dañe o amenace al bien jurídico que protege.

Cuando la acción se realizó en el mundo exterior, para que sea penalmente relevante es porque se adecuo a la situación jurídica, además lo que hizo es una violación a la norma de conducta, por lo que se originó el desvalor de acción. Por ejemplo, cuando A por medio de una pistola amenaza a B y se apodera de su billetera con la suma de 1.000,00 dólares de los Estados Unidos de América. Esta acción se adecúa (tipicidad) a la situación jurídica, que se encuentra descrita con todas sus circunstancias en el tipo penal del artículo 161, inciso primero del Código Orgánico Integral Penal, en este primer momento al ser típica, además, violenta la norma de conducta de prohibición, la cual determina que no realice el robo de cosa ajena. Éste constituye el desvalor de la acción.

En tanto el desvalor del resultado, se determina cuando la acción de apoderamiento, se consumó y produjo el resultado 
de desapropiación de la cosa que le pertenecía (billetera con los US \$1.000.00) y en ese momento, el resultado producido por la acción, sin que medie ninguna causa justa, produce una afectación al bien jurídico, que es la propiedad de B, para determinar si esa acción puede constituir una amenaza o daño con el resultado al bien jurídico.

Y, por último, el axioma de culpabilidad es un límite cuando se debe determinar que el ser humano efectivamente ha violentado la norma, con plena capacidad intelectual y que lo hizo teniendo, la comprensión de que su acto es antijurídico. No se lo puede declarar responsable, si no actuó con esta libertad de hacerlo, conforme a Derecho o en contra. Siguiendo el mismo ejemplo: A debe tener la capacidad, es decir, no debe ser ni adolescente, ni tener perturbaciones o patologías mentales, que afecten su capacidad de comprender su actuación, conforme a Derecho; y, si tiene esa capacidad, debe comprender que su actuación es antijurídica y lesiva contra el bien jurídico de $\mathrm{B}$, por lo que se le puede atribuir, reprochar o imputar el hecho típico, antijurídico.

Estos axiomas garantistas, que se describen en la norma constitucional ecuatoriana, dentro de los derechos de protección y en especial del debido proceso, llevan a observar que el Derecho penal ecuatoriano es de acto o de hecho, cuando: Nadie podrá ser juzgado ni sancionado por un acto u omisión ${ }^{4}$, es decir, que es preciso que deben existir esas dos modalidades, las cuales deben materializarse en la realidad para poder ser desvaloradas como delito.

4 Registro Oficial del Ecuador. Constitución Política del Estado. Artículo 76, numeral 3. Organización de Estados Americanos. Convención Americana de Derechos Humanos. Artículo 9. 
En el cuerpo normativo penal, se señala que: La conducta punible puede tener como modalidades la acción y la omisión ${ }^{5}$, en ese sentido, podemos ver que funciona como un límite al poder punitivo, en especial al legislativo, el cual no podrá elaborar tipo penales, sin que exista una conducta humana, que deba ser regulada.

Además, esta va a servir como elemento básico o unitario del sistema de la teoría del delito ${ }^{6}$, así como de unión entre las demás categorías dogmáticas, a saber, la tipicidad, la antijuricidad y la culpabilidad. Y, por último, servirá como delimitadora de los bienes jurídicos, que podrá afectar.

Podemos interpretar que en el momento de la decisión de redactar la norma legal penal, se ubica a la conducta en una posición amplia, que comprende las dos modalidades, pero que estas dos tienen su propia estructura ontológica y normativa de explicación para que tenga relevancia o transcendencia jurídico penal.

\section{LA OMISIÓN}

Para comprender de mejor manera el tema de la omisión, debemos conceptualizar qué entendemos como acción. MARÍA ÁngeLES RuEDA MARTín sostiene que antes que se desarrolle el sistema clásico de la teoría del delito:

5 Registro Oficial del Ecuador. Código Orgánico Integral Penal, artículo 23.

6 Rueda Martín, M. A. “La acción y la omisión”, cap. 6, en Romeo Casabona, C. M., Solá, E., y Boldova, M. (coords.). Derecho penal. Parte general. Introducción a la teoría jurídica del delito. Granada, Editorial Comares, 2013, p. 84. 
La dogmática jurídico penal se desarrolló bajo el concepto de imputación de PUFFENDORF y el concepto de la acción humana desarrollado por él. Dentro de este concepto de acción no están comprendidos todos los resultados causados por el ser humano, sino aquello que dependen de su voluntad o que son dominados por ella, de modo que solo estos resultados pueden serle imputados como su obra. Estas dos ideas son de gran importancia porque van a ser el denominador común en el concepto de imputación: por un lado, con este concepto se pretende delimitar las acciones por las que un sujeto puede ser responsable frente al caso fortuito, frente al acaso o a la causalidad, que no pueden ser exclusivo fundamento de la responsabilidad penal; por otro lado, el concepto de imputación depende totalmente de la voluntad ${ }^{7}$.

La posición de PUfEndorf se puede entender que consiguió dos logros. El primero, determinar la diferencia, entre los actos que eran imputables al ser humano y cuáles no le correspondían, como los casos fortuitos, de inconsciencia absoluta o de movimiento reflejo, que son actos en los cuales se encuentra anulada la voluntad. El segundo, cuando se pueden determinar que los actos humanos tienen una voluntad, la cual realiza y conduce hacia un fin para producir el resultado, que se encuentra previsto en la situación jurídica del tipo penal, con ello se fue abandonando el Derecho penal de autor, propio de la Edad Media.

Se conoce que, en forma posterior, se dejó de lado la teoría de la imputación, para crear la teoría del delito-punibilidad, teniendo

7 Rueda Marín, M. A. op. cit., p. 84. 
como fundamento la acción. En ese orden de ideas surge y por eso hay que tomar en cuenta el contexto histórico, en el cual se desarrolló la teoría causal de la acción.

Esta teoría se desarrolló, cuando epistemológicamente se encontraba dominado el pensamiento por el conocimiento científico positivista, por lo mismo, el positivismo era la única forma de explicación de los fenómenos, del cual el Derecho no se excluye, surgiendo y desarrollándose el positivismo jurídico legalista; en ese sentido, ingresa el modelo explicativo del sistema clásico de la teoría del delito, en el cual se busca la causa u origen que determine un resultado, por tal razón, la acción se consideraba como un simple movimiento de voluntariedad, que producía un movimiento corporal, sin ningún otro contenido.

Otro criterio para realizar la diferencia, entre la acción y la omisión, es el propuesto por ENGISCH, quien ha puesto en marcha la cadena causal mediante el empleo activo de energía y, así ha creado un riesgo para el bien jurídico protegido ${ }^{8}$. Continúa Harro OtTo, explicando que:

Este es el criterio decisivo para la acción. Si se constata que el autor no creado ni incrementado riesgo alguno para el bien jurídico protegido a través de la puesta en marcha de un curso causal, entonces se debe verificar si se le puede reprochar al autor una eventual omisión, es decir, el omitir poner en marcha una cadena causal para evitar el resultado ${ }^{9}$.

8 Отто, H. Manual de Derecho penal. Teoría general del Derecho penal. 7.a ed. Béguelin, J. R. (trad. del alemán). Barcelona, Editorial Atelier, 2017, p. 244.

9 Отто, Н. op. cit., p. 245. 
Este sistema positivista o causalista, propuesto por FrANZ Von Liszt y BeILing, se construye con los tres elementos de acción, relación de causalidad y resultado, que se resuelve en la tipicidad, y para explicar la relación causal se recupera la teoría de las equivalencias de condiciones, es decir, que todas las condiciones que pertenecen a la cadena causal, se entienden como causas; por ejemplo, lo que sostiene esta posición es que las condiciones que sirven para la fabricación del vehículo, utilizado como transporte de la droga, entiende que quienes elaboraron el automotor a pesar de que son condiciones, lo considera causas que producen el resultado de transporte de la sustancia prohibida y sometida a fiscalización, por lo que también deberán responder por el delito de transporte de droga. Esto generó una crisis de esta posición dogmática, que fue criticada por cuanto no explicaba adecuadamente la individualización del autor.

Para evitar los excesos de esta posición, existen propuestas teóricas, que aportaron criterios que sirvieron para individualizar al autor o causa, éstas son:

1. La supresión hipotética;

2. La de la causalidad adecuada, que ingresa criterios normativos ${ }^{10}$;

3. La teoría de la relevancia jurídica;

4. El sistema finalista o de la finalidad; $y$,

5. La imputación objetiva del resultado.

Al entrar en crisis este sistema causal de la acción, en los años treinta, surge la teoría finalista, que tiene la decisión metodológica de explicar desde una construcción ontológica; para WELzel

10 Rueda Marín, M. A. op. cit., p. 85. 
la acción humana es compleja y debe tener una unión entre lo subjetivo y lo objetivo y, por lo mismo, tener un sentido y no solamente un simple movimiento corporal, es decir, contar con una estructura:

1. Que la acción tiene siempre un fin;

2. Luego de la decisión del fin, retorna para la elección de los medios o herramientas idóneas que se van a utilizar para llegar a ese fin;

3. Puede prever las consecuencias de sus actos, por lo cuales puede evitarlos; $y$,

4. Conduce con lo anterior a la voluntad que es la que va a realizar, consumar y mantener el resultado del fin propuesto. Por eso se conoce a este modelo explicativo como vidente, ya que el conocimiento va a conducir a la voluntad al fin propuesto.

También, esta teoría a más de ser ontológica, tiene aportes normativos, ya que le encuentra explicación de sentido social, cuando determina que existen acciones con adecuación social (muchos autores consideran que es el inicio del riesgo permitido) y las que no tienen adecuación social, para que puedan ser penalmente relevantes; otra es la finalidad, como categoría de la voluntad, ésta es normativa por su propio contenido, ya que, como sostiene Welzel, se entiende que el hombre por su saber causal, tiene la capacidad de prever las consecuencias de sus actos y poder evitarlos, y seguir con su plan de considerarlo. Por tanto, cada uno de los criterios de este concepto tiene elementos valorativos y no solo ontológicos. La crítica recibida por lo ontológico es tan solo por una decisión metodológica, para la construcción del modelo dogmático, que sirvió para descubrir las 
inconsistencias del sistema clásico, para sistematizar y crear o reformular las ideas y conceptualizaciones existentes.

Para Roxin, una de las posiciones actuales de la acción, la considera como una manifestación exterior de la personalidad moral y espiritual del hombre. JAKOBS considera a la acción como la asunción culpable de la competencia por una lesión grave de la norma ${ }^{11}$. Por lo que RUEDA MARTín señala que estas posiciones de la imputación objetiva, lo único que hacen es paliar los efectos o las consecuencias, que ha conducido el sistema de explicación de la teoría causal de la acción, lo cual hace que prescinda de la finalidad actual del sujeto en el seno de la acción y se exige un movimiento voluntario, que causa el peligro desaprobado, según $\mathrm{FRISCH}^{12}$. La autora toma la postura por la explicación de la teoría final de la acción.

Una vez entendido qué es la acción, seguiremos con el tema propuesto, en cuanto a la conceptualización de la omisión, el sistema clásico del delito; como habíamos indicado en líneas anteriores, tiene tres ejes principales que son: la manifestación externa de la voluntad, el resultado y la relación de causalidad. Desde la explicación mecanicista, era no hacer nada, puesto que de la nada, no puede surgir nada, es decir, que como se exigía un movimiento corporal, la omisión significaba ningún movimiento corporal.

María Ángeles Rueda Martín, Radbruch y Von Liszt, ingresan en su construcción de la omisión como un no hacer algo. El segundo sostenía que la omisión consiste en no impedir,

\footnotetext{
11 Rueda Martín, M. A. p. 87.

12 Ibíd. p. 88.
} 
voluntariamente el resultado y agrega la manifestación de voluntad consiste en no ejecutar voluntariamente un movimiento corporal que debería haber realizado ${ }^{13}$.

Con la construcción de la teoría finalista, el aporte se lo hace desde una construcción ontológica de la omisión. Armin KaUfman, entrega dos criterios de imputación que son no realización de una acción finalista que el autor podía realizar y que no realizó en una situación concreta, teniendo la capacidad de realizar. Por tanto, éste no se debe considerar como un aspecto negativo de la acción, sino como delimitador ${ }^{14}$. Es decir, cuando una persona no realiza una acción que puede realizar, este es un juicio objetivo e independiente de cualquier exigencia normativa y es una acción positiva de la misma.

Parareforzaresta posición,MAURACH-GôsSELconsidera que tanto la acción como la omisión, tienen una estructura ontológica similar, tomando en cuenta que una conducta humana, psíquicamente estructurada, tiene un modo determinado, independientemente de que se persiga o no un resultado perceptible por el mundo exterior de que la omisión sea caracterizada por la ausencia de una actividad física y que pueda perfectamente constituir una acción, si se cumplen aquellos elementos esenciales de perseguir o estar dirigida a un fin, dominada por la voluntad dirigente ${ }^{15}$. Es decir, si no es acción humana, como en los casos de caso fortuito, inconsciencia absoluta o movimientos reflejos no se le pueden atribuir los actos o la inactividad, ya que se encuentra anulada su

13 Donna, E. A. Derecho Penal. Parte General. T. VI. Santa Fe, Editorial Rubinzal Culzoni, 2010, p. 201.

14 Rueda Martín, M. A. op. cit., p. 89.

15 Ídem. p. 237. 
voluntad, pero en el caso de la madre, que se duerme con el niño en su cama, esto si se puede imputar, por cuanto es una violación al deber objetivo de cuidado o como dice DonNa, con la figura penal desde la libera in causa ${ }^{16}$.

Para Welzel, la omisión está referida necesariamente a una acción, no existe una omisión en sí, sino solo la omisión de una acción determinada. Por lo tanto, la omisión no es un concepto negativo, sino solo un concepto en concreto limitativo: es la omisión de una acción posible del autor, que está subordinada al poder final potencial de la persona. Aclara que su posición, no siempre entendida, sostiene DonNA:

La omisión es la no producción de la finalidad potencial (posible) de un hombre en relación con una determinada acción. Solo aquella acción que está subordinada al poder final del hecho (dominio del hecho) de una persona, puede ser omitida ${ }^{17}$.

Y como podemos darnos cuenta a más de la construcción ontológica, existen los criterios normativos o valorativos de poder final del hecho (dominio del hecho).

En ese orden de ideas, LuZón PeÑa acepta la existencia de los criterios ontológicos y en su construcción considera que se deben complementar con criterios normativos como: si no se realiza una determinada actividad, ésta debe haber tenido la capacidad de realizarla, por lo que se considera que sea posible o esperada, o una acción determinada; sin embargo, tal expectativa

16 DonnA, E. A. op. cit., pp. 238-239.

17 Ibíd. p. 241. 
se ve defraudada. La posibilidad que determina la esperanza o la expectativa, que se refiere a una actividad positivamente valorada, y que por ello es esperada, deseada y cuya esperanza se ve defraudada, si no se efectúa ${ }^{18}$.

¿Cuándo se ve la esperanza defraudada? En un primer momento, cuando se tiene simplemente la confianza fundada en que el sujeto actúe de un modo positivo correcto. En un segundo espacio, la existencia de un deber (extrajurídico, social, ético, religioso, cuasicontractual, etc, o jurídico), que impone u obliga a la actividad. Y, por último, en la expectativa derivada de un estricto deber u obligación, jurídicamente solo se debe hablar de omisión de una conducta concreta anterior, si se la añade el requisito normativo del deber de actuar; este deber se deriva de una norma imperativa de conducta, que le ordena la realización de dicha conducta. ${ }^{19}$

Es decir, la omisión es una acción positiva, determinada por los siguientes criterios:

a) Es la no realización de una concreta acción; y,

b) Esta acción es la debida, ordenada, que era posible cumplir $^{20}$ y que era la correcta, puesto que esa es la expectativa.

18 Luzón-Peña, D. M. Lecciones de Derecho penal. Parte General. Valencia, Editorial Tirant lo Blanch, 2016, pp. 567- 568.

19 Ibíd.

$20 \quad$ Ibíd. p. 569. 


\section{EL TIPO OBJETIVO DE LOS DELITOS DE OMISIÓN PURA O PROPIA}

En lo jurídico, en los delitos propios de omisión, el tipo de la Ley describe en cada caso una determinada situación, en la que todo aquel que se encuentre en ella está obligado a realizar una determinada acción ${ }^{21}$, esto quiere decir que en el texto legal, existe una acción que se debe realizar y el autor incumple un deber normativamente ordenado o exigido de realizar que consiste en una determinada acción positiva, contando con la capacidad objetiva de realizarla; teniendo ese deber y no ejecutarla, defrauda expectativas de no realizar la conducta esperada. Por ejemplo, en el tipo penal del artículo 276 del Código Orgánico Integral Penal, se determina que: La o el profesional [...] en medicina que reciba una persona con signos de haber sufrido graves violaciones a los derechos humanos, a la integridad sexual y reproductiva o muerte violenta y que no denuncie el hecho.

Este delito es de omisión propia, por cuanto se utiliza por técnica legislativa el sistema cerrado; el deber como delito debe estar descrito en la parte especial en forma precisa para no permitir la expansión del Derecho penal. Y se opone al sistema abierto como el de la omisión impropia o comisión por omisión, que aún cuando se encuentra en la parte general, puede ser utilizada en la parte especial, pero en el Ecuador se ha limitado a los delitos contra los bienes jurídicos contra la vida, la salud y la integridad física ${ }^{22}$.

21 Отто, Н. op. cit., p. 248.

22 Registro Oficial del ECUADOR. Código Orgánico Integral Penal. Artículo 28, inciso 2. 
La estructura de todo tipo de omisión pura consta, pues, de los tres elementos siguientes:
a. La situación típica;
b. La ausencia de una acción determinada; y,
c. La capacidad de realizar la acción ${ }^{23}$.

\section{a) Situación típica o situación generadora del deber}

Para Santiago Mir Puig, en la que se omite una determinada acción, pese a que el sujeto podía haberla realizado ${ }^{24}$. ENRIQUE BACIGALUPO, sostiene que: $E l$ primer elemento del tipo objetivo de los delitos propios de omisión es la situación de hecho de la que surge el deber de realizar una determinada acción ${ }^{25}$, cuando existe la norma que determina el deber de la acción, que se encuentra descrita en el tipo penal, pone en peligro el bien jurídico protegido, ésta es omitida por el sujeto activo del delito. En este caso, sería el tipo penal transcrito para el estudio el artículo 276 del COIP, que consistiría en el deber de denunciar, en el caso de recibir a una persona que haya sido víctima de graves violaciones de derechos humanos, integridad sexual y reproductiva y vida.

23 Mir Puig, S. Derecho penal. Parte General. Buenos Aires, Editorial IB\&F, 2016, p. 325.

Ibíd.

25 Bacigalupo Zapater, E. Derecho penal. Parte General. Lima, ARA Editores, 2004, p. 506. 


\section{b) La no realización de la acción exigida por la norma}

Es la comparación de la acción que realizó el autor o el sujeto activo y la que requiere el cumplimiento del deber de actuar $^{26}$. Es decir, debemos realizar la valoración de la actuación que hicieron los médicos o el personal de salud, quienes no presentaron la denuncia ante la presencia de delitos de graves violaciones de derechos humanos [...], y la norma de conducta que les imponía un deber que corresponde a la acción debida para cumplir el mandato.

Por lo tanto, se constituye en la conducta esperada, es decir, que se entiende que una persona que tiene el conocimiento de estos hechos realice la denuncia, es la conducta esperada. Tomando en cuenta las circunstancias del texto legal, en su condición de servidores de la salud, saben y conocen en qué consisten las graves violaciones de derechos humanos, es decir, delitos de lesa humanidad, (tales como la tortura en casos que sea generalizada o sistematizada), de la integridad física (en los que también está la tortura) o los delitos de violencia sexual (violación, abuso sexual, acoso sexual e inseminación no consentida).

\section{c) La capacidad objetiva o la capacidad o poder de hecho de ejecutar la acción}

Para BACIGALUPO, consiste en la capacidad del obligado de realizar la acción mandada o de, en su caso, evitar el resultado [...] es un elemento individual ${ }^{27}$.

Ibíd.

BACIGALUPO ZAPATER, E. op. cit., p. 507. 
En ese sentido, se entiende que en esa capacidad existe la previsibilidad, requiriendose por tanto de un juicio de previsibilidad objetiva, el cual tiene dos elementos: el primero, el conocimiento que se obtiene de la experiencia, esta capacidad permite que el ser humano tenga la forma de prever para que no se produzca un resultado, es decir, que se anticipe, para que realice la acción esperada de denunciar; y el segundo, que se determine, conforme a las leyes de la época.

Además, esta capacidad también consiste en tener las fuerzas físicas y mentales mayores o menores que pueden concurrir en una persona normal ${ }^{28}$, es decir, que pueda cumplir física y/o legalmente ese deber de hacerlo, debe tener la capacidad de evitar, con su acción, que se consuma el delito y que haya decidido o tomado la decisión de la acción mandada y de realizarla ${ }^{29}$.

Si ese profesional de la salud estaba en el lugar donde se presentó esa persona, víctima de los delitos descritos en el texto legal, debe realizar la acción de denuncia. O si físicamente tiene la probabilidad de realizar la denuncia, que es la conducta esperada y que será valorada para determinar la relación normativa.

\section{d) El tipo subjetivo de los delitos de omisión pura}

Se presupone que el sujeto debe conocer los elementos del tipo objetivo del delito de omisión y debe conocer

\footnotetext{
28 Mir Puig, S. p. 325.

29 Bacigalupo Zapater, E. op. cit., p. 507.
} 
de la capacidad objetiva de realizar la acción ordenada. Cuando es doloso, el sujeto debe tener la voluntad de no realizar la acción, que debía realizar y que era esperada.

\section{EXISTENCIA DE LA CAUSALIDAD EN EL DELITO DE OMISIÓN}

Una de las discusiones es si existe causalidad o no en el delito de omisión, para Edgardo Alberto Donna, en un primer momento, no existe diferencia entre la acción y la omisión, desde una posición ontológica, por cuanto considera que:

En ambos hay voluntad y el sujeto se hace dueño de la situación, esto es, domina la causalidad en un caso y en el otro, al dejar que el curso causal prosiga. Se trata en ambos casos supuestos de una forma de decidir y, por ende la imputación debe ser al sujeto libre que decide no hacer ${ }^{30}$.

Continúa, Edgardo Alberto Donna con la posición de JoAchim HRUSCHKA, quien sostiene sobre la omisión propia o impropia:

En primer lugar, no hay duda de que, como se verá, existe causalidad en el sentido de que el sujeto nada hace para evitar que siga el curso causal iniciado que daña al bien jurídico. En segundo lugar, para que al autor se le pueda imputar la conducta, debe tener el dominio del hecho, como cualquier autor, y en los delitos de comisión por omisión debe estar colocado en una posición en la cual el dominio del hecho en

30 DonnA, E. A. op. cit., p. 191. 
relación con el bien jurídico le obligue intervenir, que no es otra cosa que la posición de garantía ${ }^{31}$.

En la posición de que no existe causalidad, se encuentra Roxin, quien sostiene:

La ciencia se esforzó tratando de probar la existencia de dicha fuerza causal en la omisión. Estos esfuerzos han fracasado, por tanto, no requieren de descripción más precisión. Y por último, sostiene que: la causalidad en la omisión consistiría en la supresión de un impulso de actuación y generaría realmente el resultado al eliminar un factor (la voluntad de actuar) impediente de dicho resultado. [...] afirmaba que: podría existir en la omisión una causalidad en relación con el resultado, ya no es más defendida ${ }^{32}$.

Continúa Roxin: [...] que no existe una causalidad en el estado natural como se prende sostener, ya que no existe las energías o fuerzas eficientes o dinámicas de la causalidad, ni siquiera en los delitos de acción, por lo que termina sosteniendo que: Es aconsejable aplicar la fórmula de la causalidad como condición legal tanto a los delitos de acción como a los delitos de omisión $^{33}$.

31 LuZÓN-PeÑA, D. M. op. cit., p. 195.

32 DonnA, E. A. op. cit., p. 202.

33 Ibíd. pp. 208-209. 
En ese mismo sentido, EnRique Gimbernat Ordeig, sostiene que:

Entre la omisión y el resultado no puede existir relación de causalidad, ya que en un sentido científico natural la omisión no causa nada. Porque la ausencia de energía (y la causalidad mediante el empleo de energía influye materialmente en el resultado) la inactividad no pone en marcha cadenas causales. Solo cuando haya causado el resultado mediante una inactividad, sino solo que se hubiera actuado habría impedido el resultado ${ }^{34}$.

Donna, critica las posiciones anteriores, (de RoXIN y GIMBERNAT) y sostiene que: el problema causal en la omisión esconde otro que es el de la valoración. Por ejemplo, si la madre hubiera actuado dando de alimentar a su hijo, hubiera evitado el resultado de la muerte. Si se hubiera actuado, se habría salvado. Esto no es casual, es valorativo, sujeto a prueba, condicional, que el Juez debe necesariamente valorar, pero que con seguridad en pocos casos se sabrá. ¿Que se quiere decir con esto?, ¿que siempre existirá valoración? El problema es cuando se la esconde ${ }^{35}$.

Quienes se oponen a la causalidad, argumentan que existe una cuasi causalidad, una causalidad hipotética o simplemente una imputación objetiva del resultado ${ }^{36}$.

\footnotetext{
34 Ibid.

35 DonnA, E. A. op. cit., p. 211.

36 Ibíd. p. 204.
} 
Edgardo Alberto Donna cita a Ingeborg Puppe, quien manifiesta que la omisión como causalidad, puede ser parte de una ley general de condiciones que lleva a un resultado. Como en los delitos de acción, se trata de condiciones reales, que no son solamente lógicas, sino que dependen de relaciones causales.

Defiende que en la acción como en la omisión, el estado de las cosas puede ser real. Por eso PUPPE recurre a la acumulación de causas en la omisión y a la teoría de las condiciones mínimas, ya que considera que deben existir estas condiciones mínimas que se dan por la experiencia, para no evitar el resultado, si el garante hubiera cumplido con su deber ${ }^{37}$.

Podemos concluir que para que exista causalidad, debe existir la valoración de las condiciones mínimas de actuación por parte del autor de interrumpir el resultado con la conducta que podía realizar y que era esperada.

La posición de garante solo se puede discutir cuando existe la posibilidad del omitente de evitar el resultado, ya que nadie está obligado a realizar actividades sin sentido. En esta dirección, lógicamente deben ser estrictas las condiciones del origen o de la formación de un deber del garante al igual que la causalidad, a través de la omisión. Sin embargo, desde otra perspectiva, ésta se relaja, ya que el garante debe actuar no sólo cuando el resultado con seguridad se puede evitar, sino también cuando existe una oportunidad de salvación, aunque se debe aceptar que ello únicamente se exige, en tanto le sea posible al garante el cumplimiento del deber ${ }^{38}$. (caso de Lederspray)

\footnotetext{
$37 \quad$ Ibíd. p. 213.

38 Donna, E. A. pp. 213-214.
} 
Una vez explicadas la posiciones de esta discusión, DonNa concluye que no se debe ver la causalidad en forma natural, sino que debe existir una relación normativa. La causalidad se da por la existencia de la libertad, debe existir voluntad, y que el sujeto pueda manejarla, es decir, debe existir el dominio del hecho de no realizar el deber que se le exige, por tanto, existiendo dolo, puesto que tiene el conocimiento de la situación jurídica y de las consecuencias por la negativa de hacerlo, teniendo la posibilidad para realizarlo, porque domina el suceso en su plenitud ${ }^{39}$.

\section{DELITOS OMISIVOS IMPROPIOS O DE COMISIÓN POR OMISIÓN}

Antes de ingresar al estudio del delito de omisión impropio, me permite el lector presentar ¿cuál es el problema dogmático de este delito? EnRiQue Bacigalupo lo presenta cuando cita el artículo 11 del Código Español, el Legislador reguló este delito: No impedir un resultado es equivalente a su producción activa. Podemos sostener que existe una similitud con lo descrito en el artículo 23, inciso segundo del CoIP: No impedir un acontecimiento cuando se tiene la obligación jurídica de impedirlo equivale a ocasionarlo. El ejemplo conocido, en todos los manuales de Derecho penal: la madre, asfixia a su hijo de tres meses de edad con una almohada, (causar la muerte a otro); la madre, deja morir de hambre a su hijo de tres meses de edad, (es decir, no impidió que muera de hambre). El problema, como sostiene BACIGALUPO, es como llevar a cabo esta diferenciación ${ }^{40}$.

\footnotetext{
39 Ibíd. p. 216.

40 Bacigalupo, E. op. cit., p. 509.
} 
Continúa el autor argentino, mencionando que:

Inicialmente no existía ninguna dificultad para establecer la equivalencia entre producir(activamente) un resultado y no impedirlo, pues se entendió que la omisión podía ser una causa del resultado y que no impedir la interrupción del aborto, las lesiones corporales, etc. realizaría el tipo de aborto de la misma manera como si se lo realizaría en la forma activa $^{41}$.

Explica además BACIGALUPO: lo que reclama la Justicia, por lo tanto, se podría expresar técnicamente a través de la causalidad $^{42}$. Es decir, que esta la forma como desde la teoría clásica o positivistas (causalista) encontrar los criterios para poder solucionar dogmáticamente el problema planteado. Sin embargo, sostiene que: desde la causalidad no es lo mismo causar que no impedir, es decir, no es lo mismo matar que no impedir morir ${ }^{43}$. Por lo que concluye que: de la nada no surge nada, ya que, además, del tipo penal se requiere una causalidad de una manera explícita o implícita la solución causal resulta totalmente inidónea.

En ese sentido, se generó una crisis del modelo, por lo que se buscó una solución para que las omisiones que implicaran la infracción de un determinado deber de actuar deberían ser típicas. Por ello se renunció a la causalidad y se reemplazó por la antijuricidad de la omisión como elemento decisivo de la equivalencia entre
41 Ibíd.
42 Ibíd.
43 Bacigalupo, E. op. cit., p. 509. 
causación y no evitación del resultado ${ }^{44}$. Así surgió la teoría de las fuentes formales en buscar el fundamento y legitimidad de la institución de la posición de garante: que se convierte en el fundamento del deber cuya infracción determina la equivalencia entre el comportamiento típico activo y la no evitación del resultado. (ingresaron los deberes éticos sociales) $)^{45}$.

Harro Otto y Edgardo Donna sostienen que no es un problema dogmático, sino más bien es un problema de valoración, al considerar que:

En los delitos impropios de omisión no hay un tipo penal que indiscutiblemente conmine con pena una determinada omisión. La interpretación de los tipos que, en primer lugar, son considerados como delitos de comisión conduce luego al entendimiento de que, en ellos, que observados superficialmente prohíben determinado hacer, también debe ser comprendidos determinados modos de omitir ${ }^{46}$.

En ambos casos, se puede sostener que la madre ha matado a su hijo, por lo que se puede determinar que en los tipos de la ley llamados delitos de resultado evidentemente describen un determinado comportamiento que puede ser realizado por comisión por omisión ${ }^{47}$. Pero como sostiene tanto Harro OTTO, como EdGARdo Donna, el problema no radica en la descripción de la conducta, sino que la omisión recae en una determinada

\footnotetext{
44 Ibíd.

$45 \quad$ Ibíd. p. 512.

46 Otto, H. op. cit., p. 249.

47 Ibíd.
} 
persona $^{48}$. Este criterio será el más representativo para valorar la existencia del delito comisivo de omisión y a la vez se constituye el elemento valorativo central para determinar la equivalencia entre la omisión impropia y la comisión. Es decir, para ser autor del delito de comisión por omisión, no puede ser cualquier persona, sino un grupo reducido de personas, por su especial posición de garante.

Como otra forma de construir el delito de comisión por omisión Mir Puig, sostiene que el delito tiene los mismos elementos del delito propio de omisión, que son: a. situación típica, b. ausencia de la acción determinada; c. capacidad de realizarla; pero complementada con la presencia de tres elementos particulares necesarios para la imputación objetiva: la posición de garante, la producción de un resultado y la posibilidad de evitarlo ${ }^{49}$. Además, este autor en su construcción considera que la posición de garante es el elemento indispensable para la equiparación entre la omisión y la acción, ya que sostiene que la normativa penal española no puede quedarse en la descripción formal del deber jurídico y no desarrollar la posición de garante, por lo mismo llama a encontrar el fundamento en la posición de garante en las funciones que este cumple como son la protección y el control de las fuentes de peligro que pueden afectar el bien jurídico tutelado ${ }^{50}$.

Diego Manuel Luzón Peña, considera que los requisitos de las omisiones propias son en parte aplicables a la omisión impropia y en parte no, en la medida que la omisión impropia, aunque acabe en una comisión, comienza siendo una omisión, es decir,

\footnotetext{
48 Ibíd.; DonNA, E. A. op. cit., p. 258.

49 Mir PUig, S. op. cit., p. 327.

50 Mir PUIG, S. op. cit., p. 329.
} 
el incumplimiento de un deber de actuación, ha de reunir los requisitos básicos de toda omisión, a saber: la existencia de un deber jurídico de actuación y la no realización de la misma, así como, muy especialmente, la capacidad individual de realizar la acción requerida ${ }^{51}$.

Así mismo, Diego Manuel Luzón Peña, considera que se deben complementar otros requisitos adicionales:

a. Debe existir la producción de un resultado;

b. El deber jurídico especial de evitar o interrumpir el resultado típico.

Es decir, un deber de garantía, por lo que no podrá ser autor cualquier persona sino solo quien tenga la posición de garantía jurídica; $y$,

c. Así como la concurrencia de las circunstancias que permiten fundamentar el criterio de equivalencia material con la comisión activa, por la creación o aumento del riesgo permitido por la omisión misma $^{52}$.

De las posiciones presentadas, en primer lugar, no existe un delito de comisión por omisión, lo que existe es el tipo de acción u omisivo, y que este se puede consumar por ambas modalidades, en el ejemplo propuesto, el homicidio se puede cometer por ambas formas, el uno en forma activa causando la muerte y el otro omitiendo la acción para evitar que se produzcan el resultado. En segundo lugar, reconocen que deben ser solo en delitos que tiene un resultado lesivo para el bien jurídico, se entiende que se excluyen

\footnotetext{
51 LuZÓN-PEÑA, D. M. op. cit., p. 589.

52 LuZÓn-Peña, D. M. op. cit., p. 589.
} 
los delitos de resultado formal o de peligro abstracto y concreto. En tercer lugar, el autor debe tener una relación o posición de garantía jurídica con el bien jurídico. Es decir, una posición de garante. Diego Luzón Peña, Mir Puig, Harro Otto y Donna, consideran que esta posición de garante no es fundamental, sino solamente restrictiva, que limita la actuación a las personas que se encuentran en esta posición, no es para todos.

Por último, debe existir el deber jurídico de impedir o evitar el resultado, que se encuentra implícitamente en el tipo penal, fijado en la norma, por lo que se debe encontrar su fundamento en las funciones de protección y control.

No debemos olvidar, que en los planteamientos de LuZón PEÑA y BACIGALUPO, existe la categoría dogmática de la equivalencia, quienes consideran que debe existir criterios de imputación objetiva para poder determinar la imputación al autor el resultado. Aunque estimo que en las otras posiciones también existen, ya que, la discusión se centra en como determinar la equivalencia entre acción y omisión impropia; al dar énfasis en la posición de garante, también está implícita la equivalencia, tomando en cuenta que es la equivalencia de haber actuado y de haber evitado en función de protección y de control de las fuentes de peligro.

A pesar de que la discusión también se da sobre la existencia o no de la causalidad, todos tienen claridad al sostener que no existe una causalidad real, sin embargo, Отто sostiene que deben haber además ciertas condiciones mínimas, pero que existe una causalidad jurídica o imputación valorativa. Por ello es que se buscan encontrar criterios valorativos para determinar la imputación de la omisión al resultado. Santiago Mir Puig y Diego Luzón Peña, incrementan los criterios de imputación objetiva. 
Lo que están procurando todos es encontrar la categoría de la equivalencia de los delitos de comisión con los delitos comisión por omisión. Con el criterio de la posición de garante.

El Código Orgánico Integral Penal, tiene dos descripciones referentes a la omisión impropia. La primera, hace referencia a que: No impedir un acontecimiento, cuando se tiene la obligación jurídica de impedirlo, equivale a ocasionarlo. ${ }^{53}$ Este mismo texto legal, encontramos en el Código Penal italiano, y es visto por Giovanni Fiandaca y Enzo Musco, como que se trata del delito de comisión por omisión u omisión impropia. La segunda, la omisión dolosa describe el comportamiento de una persona que, deliberadamente prefiere no evitar un resultado material típico, cuando se encuentra en posición de garante.

Podemos sostener, después de realizar una interpretación de la redacción del texto de la norma, con el marco teórico que se va a estudiar que la omisión dolosa, es la omisión impropia. Además, el primer texto, tiene una referencia a la posición positivista o causalista de las escuelas del delito como lo sostuvo BACIGALUPO, ya que requiere de la causalidad, al momento que se utiliza el termino de equivalencia y además se incluye el elemento de contar con la obligación jurídica de impedirlo.

53 Los autores italianos indican que el artículo 40, párrafo 2..$^{\circ}$ del Código Penal italiano, que reza así: No impedir un evento que se tiene la obligación jurídica de impedir, equivale a ocasionarlo, determina que este es un elemento del delito de omisión impropio. Es buscar la imputación jurídica de la equivalencia, a través de la posición de garante. Registro Oficial del Ecuador. Código Orgánico Integral Penal. Artículo 23, inciso 2; FiandacA, G. y Musco, E. Derecho Penal. Parte General. Eiroa, P. (trad del italiano). Santa Fe de Bogotá, Editorial Temis, 2006, p. 586. 
Pero que ha evolucionado esta categoría, para terminar, siendo el criterio fundamental para la construcción de la comisión por omisión, ya que se debe buscar la equiparación de la acción con la omisión.

En el segundo texto, se ha eliminado la institución de la equivalencia, y se incluye la normativa cuando se describe: prefiere no evitar el resultado material típico, cuando se encuentra en posición de garante. Pero considero que existe implícitamente el criterio de la equivalencia tomando en cuenta que la posición de garante es la forma de valorar la actuación de causar con la de evitar.

Además, en los textos de los artículos 23 y 28 del Código Orgánico Integral Penal, se halla en un primer momento que esa normativa, determina como criterio de equivalencia a la posición de garante como lo que se tiene que valorar. Encontrándose además fuentes formales y materiales; las primeras, la Ley y el contrato, cuando se estipula la obligación legal o contractual de cuidado; así como también el principio de injerencia, cuando se redacta: ha provocado o incrementado precedentemente un riesgo que resulte determinante en la afectación de un bien jurídico; las segundas de protección y de control se encuentran cuando se redacta: custodia del bien jurídico vida, salud, libertad e integridad personal del titular de bien jurídico.

No existe en la redacción el control de la fuente de peligro, sin embargo, estimo que debe ser recogido este criterio que la dogmática aporta, ya que con ello se cumpliría la mínima la intervención estatal, cuando se afecta solamente bienes jurídicos. 
Estimo además que debemos complementar las dos normas para poder ser aplicadas, tomando en cuenta que entre más límites se puedan imponer al poder punitivo, es más favorable para el procesado.

En este orden de ideas, los requisitos del delito impropio de omisión, serán los siguientes:

a. La presencia de un resultado material típico. Esto tiene relación con los bienes jurídicos descritos en el segundo inciso y que son: la vida, salud, libertad e integridad personal.

b. La ausencia de la acción que debe evitar el resultado.

c. Teniendo la capacidad individual de hacerlo.

d. La posición de garante, $y$,

e. La equivalencia de la omisión impropia con la acción, cuando el no evitar el resultado equivale a ocasionarlo.

Tomando en cuenta lo expuesto, debemos considerar que el tema para delimitar este delito impropio de omisión, es la posición de garante, determinando en un primer momento las fuentes tanto formales como materiales que sirven de fundamento para la construcción de ésta; así como los criterios de imputación para determinar la equivalencia, pero además, los criterios de la dogmática a pesar de no encontrarlos en el la Ley ecuatoriana. Estos deben ser tomados como esas reglas técnicas que nos ayudaran a comprender mejor y poder aplicar la ley de mejor manera para evitar excesos e impunidad en los casos de omisión impropia. Por eso es importante entender esta posición de garante para desarrollar contenido en nuestra ley y en los fallos de nuestros jueces. 


\section{LA POSICIÓN DE GARANTE}

SAntiago Mir Puig, considera que, si el primer elemento de toda omisión es que tenga lugar la situación típica base del deber de actuar, en la comisión por omisión no expresamente tipificada ha de integrar dicha situación llamada posición de garante por parte del autor. La cual se da cuando corresponde al sujeto una especifica función de protección del bien jurídico afectado o una función personal de control de una fuente de peligro, en ciertas condiciones. Ambas situaciones convierten entonces al autor en garante de la indemnidad del bien jurídico correspondiente ${ }^{54}$.

\section{1. Fuentes formales}

A continuación realizaremos una descripción de las fuentes que sirven como fundamento a la construcción de la posición de garante, los aportes y su evolución histórica dogmática.
Los delitos de omisión impropia consisten en que el autor, a través de su omisión, causa el resultado previsto en el tipo penal, y está en una posición de evitar la entrada de ese resultado, es lo que se llama la posición de garante ${ }^{55}$.

La teoría clásica o positivista del delito, construyó para poder lograr resolver los casos en concreto, como lo sostuvo BACIGALUPO, que esta posición deriva directamente de las teorías causales y de la búsqueda en consecuencia de un fundamento causal de la omisión impropia. Estas son las fuentes formales, la

\footnotetext{
54 Mir PUIG, S. op. cit., p. 327.

55 Donna, E. A. op. cit., p. 260.
} 
causa del resultado. Estas son la Ley, el contrato, la actuación precedente incrementando el riesgo, pero la idea de esta posición era que atendía de manera unilateral a las fuentes de la posición de garantía, de modo que descuidaba ostensiblemente la posición del sujeto en relación con el bien jurídico ${ }^{56}$.

Esta fue una de las críticas recibidas y que fue acumulándose a otras, como las explica EDGaRdo AlBERTo DonNA ${ }^{57}$, estas teorías formales, tuvieron dificultades y ambigüedades, al momento de ser aplicadas y exponen sentencias del Tribunal Alemán, de 4 de enero de 1932, que sostuvo el criterio de la posición de garante, en la que se fundamentó: El deber del padre natural en relación con el cuidado del recién nacido no en el hecho anterior, sino en la voluntad de la comunidad. Asimismo, en otro caso, se dictó sentencia llegando al extremo de hacer responsable al esposo como encubridor de su mujer si no se oponía a la prostitución de la mujer, o el caso, de sentenciar al esposo en calidad de participe si no impedía el delito de perjurio de su cónyuge.

Como explica Отто, otras críticas a esta posición se dieron cuando, por ejemplo, en la relación de manutención entre parejas que no tenían vínculo matrimonial celebrado bajo la legalidad, sino solamente la relación de comunidad, generándose una discusión de que si dichas relaciones como no tenían el reconocimiento legal no se justificaban los deberes jurídico-civiles de evitación de los resultados ${ }^{58}$. Así mismo se demostró que la celebración de un contrato que no se encuentre firmado por la persona titular de la capacidad legal, generando que no tenga validez jurídica, por

\footnotetext{
56 Schunemman, B., en DonnA, E. A. op. cit., p. 261.

57 Donna, E. A. op. cit., p. 262.

58 Отто, Н. op. cit., p. 252.
} 
lo que un salvavidas o una enfermera o una niñera, no asumirían el deber jurídico de evitar el resultado de muerte.

Con los ejemplos expuestos, se considera que el modelo explicativo no es suficiente, por lo mismo surgen la posiciones de buscar la materialidad de esa posición de garantía.

\section{2. Fuentes materiales}

Armin Kauffman, sostiene que: la singularidad dogmática de los mandatos de garante reside en la posición especial del sujeto del mandato, de la que fluye la relación de garantía entre el bien jurídico y el obligado ${ }^{59}$. En ese sentido este autor determina que la posición de garante nace de la relación con el bien jurídico, por lo que no es un problema dogmático, en cuanto a su construcción, sino en relación a la valoración ya que:

Además, de ser un delito especial, requiere una relación singularmente estrecha del especial sujeto del mandato con el bien jurídico garantizado, una posición del obligado que, por contenido del injusto y de la culpabilidad, justifica su equiparación de omitir impedir el resultado con ejecutarlo. Cuando se da tal posición de garante que sustenta la equiparación en cuanto al merecimiento de pena constituye una cuestión valorativa, un problema axiológico y no dogmático ${ }^{60}$.

59 Kaufmann, A. Dogmática de los delitos de omisión. Madrid, Editorial Marcial Pons, 2006, p. 282.

60 Ídem. p. 283. 
Una vez determinada su posición, en la construcción del delito de omisión impropia, este autor alemán, entrega dos criterios para delimitar de mejor manera esa relación que debe existir entre el garante y el bien jurídico ${ }^{61}$, los que se exponen de la siguiente manera:

La primera, es cuando el sujeto del mandato debe observar una posición de estar vigilante para proteger determinados bienes jurídicos contra todos los ataques. Aquí tiene la función de protección que consiste en la defensa en todos los flancos del bien jurídico concreto contra peligros de todo género. Estas obligaciones pueden estar reconocidas por mandatos legales, así como generados por la asunción fáctica de deberes contractuales. Por ejemplo, en este criterio de imputación, es la relación que existe entre el deber jurídico de proteger los bienes jurídicos de sus hijos por parte de la madre o de el padre. El caso de que la madre no da de alimentar a su hijo y este muere de hambre; en el caso de que el tío queda al cuidado de su hijo de siete años y debe protegerlo del ataque de un perro; o en el caso de que las cajeras de un banco tengan las claves de apertura de la bóveda y no activen los botones de aviso a las autoridades (botones de pánico) y con ello permitan robar el dinero de dicha bóveda.

La segunda es el que puede consistir en la supervisión de determinadas fuentes de peligro, no importando que bienes jurídicos amenacen peligros desde esta fuente, el deber es el de poner coto a la concreta fuente de peligro. Por ejemplo, en el caso de que el chofer de un vehículo de transporte de pasajeros, debe tener el control de la fuente de peligro, puesto que debe realizar la revisión y el mantenimiento de dicho vehículo; o en el

\footnotetext{
61 Ídem. pp. 289-291.
} 
caso del control de un animal feroz, como puede considerarse a un perro agresivo.

Una variante a esta posición es la propuesta por BERND SCHÛNEMANN, quien acepta el aporte de Welzel, la teoría final de la acción tuvo la posibilidad de dar una solución específicamente penal del problema de la equiparación con ayuda de la teoría del dominio de hecho ${ }^{62}$, manifestando que: El dominio sobre el fundamento del resultado, asentado en la lesión que supone al bien jurídico, y con el sustento de la doble vertiente de desamparo del bien jurídico y el dominio material sobre el foco de peligro ${ }^{63}$.

El autor alemán, considera que el dominio de hecho, tiene como fundamento para la categoría de los garantes, y no como una categoría superior, sino como un caso particular de equiparación en los delitos de resultado y este dominio está relacionado con la construcción dogmática de ámbito de dominio social, criterio ampliamente aceptado por la dogmática penal. Este autor considera que esta posición del dominio tiene que ser concretada con el fundamento del resultado. Que es diferente a otras posiciones que buscan el dominio como el medio de salvación, provocando una mezcla entre dominio y monopolio ${ }^{64}$.

SCHÛNEMMAN, para resaltar la igualdad entre acción y omisión, presupone:

62 Donna, E. A. op. cit., p. 296.

63 Morillas Cueva, L. Derecho penal. Parte general. Madrid, Editorial Dykinson, 2018, p. 412.

64 SChûnemann, B. Fundamento y límites de los delitos de omisión impropia. Madrid, Editorial Marcial Pons, 2009, p. 292. 
Un dominio sobras las condiciones del resultado actuales, efectivas, y que incluso el dominio monopolístico sobre un mero medio de salvación únicamente puede fundamentar la especial reprochabilidad, pero nunca la igualdad de la omisión a la comisión. Ahí si reside precisamente sólo el dominio potencial sobre el resultado, que se encuentra en relación de desigualdad con el dominio actual presente en la acción, y que nunca puede ser equiparado con él ${ }^{65}$.

\subsection{Fuentes materiales $y$ formales}

Una tercera posición es la que aportan MAURACH-GôsSEL y Jesckeck-Weingend, según lo expone Edgardo Alberto DONNA, quien sostiene que en los dos primeros la posición de garante se construye con base a lo que se llama la teoría material-formal, que es la que da con la esencia de esta categoría jurídica.

La teoría es material, habida cuenta de que desde este punto de vista logra establecer las relaciones con respecto al bien jurídico lesionado. Pero, además, es formal debido a que considera fuentes de estas relaciones materiales, es decir que se considera que la posición de garante surge de los cánones clásicos (la ley, la libre aceptación, la comunidad de vida, la injerencia y por último de la combinación de estas) alguien debe ocupar una posición de protección 
de determinados bienes jurídicos o de vigilancia de ciertas fuentes de peligro ${ }^{66}$.

El aporte de JESCKECK-WEINGEND es que estructura las fuentes formales como un criterio de equivalencia, tomando en cuenta que deben surgir de la delimitación de las personas que deben dedicarse de un modo especial a la protección del bien jurídico puesto en peligro y que todo el resto de copartícipes confían $y$ pueden confiar en la intervención activa de una persona ${ }^{67}$. Claramente la propuesta tiene una tendencia mixta entre lo formal y lo material. Entendiéndose los niveles de la equivalencia entre la acción y la omisión, existiendo la diferencia entre actuar entre dar muerte y evitar la muerte. Lo que hace surgir es que el tema principal de la omisión por comisión es buscar la equivalencia entre ella y la acción, buscando criterios valorativos para poder determinar que esa omisión impropia se le debe imputar ese resultado.

En ese orden de ideas, la discusión en la construcción de la comisión por omisión, es como entender la posición de garante y los criterios que sirven para delimitar esta categoría dogmática, para lo cual se han creado los criterios de valoración de las fuentes formales y materiales.

En las siguientes líneas, expondremos que, ante la negativa de la causalidad en los delitos de comisión impropia, surgen las teorías de la imputación objetiva para entregar los criterios de valoración para la construcción de los delitos impropios de omisión.

\footnotetext{
66 Donna, E. A. op. cit., p. 265.

67 Ibíd. p. 266.
} 


\section{4. Imputación objetiva}

La posición de Diego Manuel Luzón-Peña, considera que no es defendible la existencia de la causalidad, ni real, ni hipotética o conforme a leyes (naturales), porque considera que existen dos obstáculos: el primero, que para que exista una modificación solo puede existir una causalidad material o causalidad psíquica, la primera, como resultado de la modificación o cambio del estado de las cosas, con la irrupción o entrada en el mismo de una energía proveniente de un proceso natural o de un acto humano (energía física, como movimiento, de golpe, calor, frío, electricidad, o reacción química); la segunda, se puede presentar como la adición de un acto humano o de una nueva situación capaz de influir mentalmente en el comportamiento o decisión de otro ${ }^{68}$.

Y la segunda objeción, es que la valorativa tampoco tiene una fuerza o energía que pueda afirmar que una omisión es causa de un resultado, por lo que no tiene una entidad real que produzca lo dicho. Es decir, que si existiera la valorativa sería una cuestión de una conducta salvadora debida o que habría sido omitida para evitar el resultado, eso mismo se lo podría decir en una omisión pura. Por lo que concluye, que la posición de garante no es fundamental sino solo es restrictiva, que ayuda a identificar cuando se debe entender como omisión impropia teniendo los criterios de agravación o cualificado en un delito comisivo ${ }^{69}$.

Para SAntiago Mir Puig, en cuanto a la imputación objetiva, considera que existe una causalidad hipotética en el momento de no evitar, ya que no existe la causalidad real entre la acción y el

\footnotetext{
68 LuZÓn PeÑA, D. M. op. cit., p. 592.

69 Ibíd. p. 593.
} 
resultado, por lo que considera que debe existir una imputación objetiva del resultado. Por lo que en su construcción considera que la posición de garante confirma la necesidad de distinguir entre relación de causalidad (como cuestión naturalística) e imputación objetiva (como cuestión normativa) ${ }^{70}$. Por eso considera que son necesarios los criterios de imputación objetiva, propuesta realizada en la exposición de su modelo.

Considera LuZÓN-PEÑA ${ }^{71}$ que al no existir esta causalidad, lo que puede o debe existir para un delito consumado es una imputación jurídica, es decir, imputación objetiva de ese resultado a la omisión impropia.

Existen dos criterios de imputación objetiva:

1. Creación o aumento del riesgo o peligro relevante.

2. Tiene que haber Imputación Objetiva de la violación del resultado como realización del peligro de la omisión.

\section{a) Creación de riesgo o peligro relevante}

Debe ser la conducta omisiva la que produzca una creación de riesgo, como debe entenderse: en primer momento debe existir la adecuación, es decir, la creación de un riesgo o peligro relevante, en la comisión por omisión, es el criterio decisivo de equivalencia con la comisión activa; que desde un baremo socio-normativo pueda afirmarse que la propia omisión crea un peligro:

1. Prácticamente inexistente o conjurado hasta el momento; y,

\footnotetext{
70 Mir PUig, S. op. cit., p. 339.

71 LuZÓn PeÑA, D. M. op. cit., p. 593.
} 
2. El descontrol o no afrontar aumenta el riesgo (crea más riesgo) existente, pero que se daba por seguro que estaba controlado o suficientemente enfrentado ${ }^{72}$.

En el primer presupuesto, de acuerdo con LuZÓN-PEÑA, se debe entender que la persona que asume este reconocimiento social de que debe tener la posición de garante, su intervención no será de crear, sino de mantener que el peligro o riesgo que esta controlado o que no existe, no aumente, sino más bien continúe en la posición de disminución. Y en el segundo presupuesto, se entiende que la persona debe actuar en forma clara, para evitar el resultado, realizando acciones para tener bajo control esa fuente de peligro o, en su defecto, afrontar en forma activa que el riesgo no aumente.

\section{b) Del resultado como realización del peligro de esa omisión}

En esta parte ingresa el criterio sobre el grado de probabilidad o seguridad con el que la acción debida había impedido el resultado para la imputación, solo se requiere una probabilidad de que la conducta debida hubiera evitado el resultado, es decir, una simple disminución del riesgo con la conducta requerida y omitida para imputar el resultado ${ }^{73}$.

LuZÓn-PeÑA indica que el mismo Roxin defiende para la omisión impropia una posición intermedia: habrá imputación del resultado si ex post es realmente verificable una disminución del riesgo; con la acción omitida sólo parecía posible ex ante, pero

\footnotetext{
72 Ibíd. p. 594.

73 LuZÓN-PEÑA, D. M. op. cit., p. 594.
} 
no consta con probabilidad basada en la seguridad, que la acción debida hubiera influido en el curso causal y evitado el resultado, por tanto, no habrá imputación ${ }^{74}$.

La posición de garante o deber jurídico especial de evitación ha sido una exigencia doctrinal para restringir el cúmulo de autores que la omisión de evitar un resultado típico es mucho más grave que el cuidado y se ha considerado imprescindible para poder imputarle el resultado como si él lo hubiera causado con su actividad. La posición de garante es una condición necesaria pero no suficiente, por ese motivo debe tener los criterios de protección del bien jurídico y de control de la fuente de peligro ${ }^{75}$.

\section{5. Fundamentación jurídico formal y ético social de los deberes de garante}

Según hemos observado la evolución de las fuentes de la posición de garante, se ha analizado que no son suficientes y que se han necesitado que esos criterios se interrelacionen para mejorar la imputación y que no se dejen situaciones de realidad en la impunidad.

En ese sentido HARro OTTO, propone dentro de esos criterios de carácter formal jurídico y ético social (material), que se sustentan en sub criterios de responsabilidad y de confianza ${ }^{76}$, que son los que se deben ir concretando de mejor manera; el primero, que la persona asume el deber de responder y proteger o controlar el bien jurídico que se encuentra bajo su relación directa sea

\footnotetext{
74 Ibíd.

75 LuZÓn-PeÑA, D. M. op. cit., p. 594.

76 Отто, Н. op. cit., p. 252.
} 
por cuestiones de índole formal o no. Y el segundo, es el que la sociedad tiene sobre la persona, que tiene la protección o el control, la confianza de que va actuar para evitar el resultado en contra de ese bien jurídico.

Por ese motivo, estos deberes éticos sociales deben servir para entender que la sociedad entrega criterios de responsabilidad y confianza a los individuos, que estos en los roles que asumen en su convivencia social deben actuar en cada una de esas posiciones, conforme a las expectativas que espera la sociedad; por ese motivo, HARRO OTTO propone tres elementos, que caracterizan al concepto propuesto por DABRENDORF ${ }^{77}$ :

a) Los roles sociales son prescripciones de conducta independientes del individuo.

b) Su contenido no es definido por el individuo, sino por la sociedad.

c) Las expectativas de conducta atañen al individuo con una cierta obligatoriedad de la pretensión, de la que este no puede sustraerse sin daños.

Explica el autor alemán que las cuestiones de las expectativas de los roles entregadas por la sociedad, no ayudaron a resolver los problemas de la omisión, debido a dos criterios: el primero, en lo jurídico, se confían todavía en la construcción en la actuación del deber jurídico de responsabilidad para conducir los modos de comportamientos en el ámbito social. Y, por otra parte, desde los roles, la posición también es muy extensa, la cual no

Отто, Н. op. cit., pp. 253-254. 
permite determinar una zona límite, que debe convivir con las expectativas individuales y que no se toman en cuenta.

Esta posición de los roles también es criticada por SCHÛNEMANN, el rol, como modelo ético-social de conducta, no es fundamento sino mera consecuencia de la posición de garante surgida de la relación de dominio, de manera que a cada categoría de garante le corresponde un rol, pero en modo alguno puede considerarse el rol como ratio essendi, ni siquiera como ratio cognoscendi de posiciones de garante ${ }^{78}$.

Por eso Отто, hace una propuesta de la posición de garante, en los siguientes términos;

a) Solo entran en consideración aquellas expectativas dentro de la vida social que en general son esperadas en determinadas posiciones;

b) La expectativa debe presentarse como exigencia de comportamiento que tiene que ser cumplida obligatoriamente (deber-expectativa) de manera tal que su cumplimiento seguirá siendo esperado a pesar de las decepciones en casos individuales;

c) La expectativa tiene que corresponderse con una expectativa recíproca de la expectativa de manera tal que en la ejecución practica de la vida social se compruebe que la conducta se organizará según las expectativas reciprocas;

78 SCHÛNEMANN, B. op. cit., p. 294. 
d) Las expectativas deben tener una solidez y de tal peso que su infracción signifique un daño para la base de confianza de la vida social de la misma envergadura que la infracción a esta base por la puesta en peligro y lesión de un bien jurídico particular mediante comisión positivas; $y$,

e) Si se respeta las líneas generales y se utiliza el material ya elaborado por la doctrina y la jurisprudencia para la concreción en el caso particular, y si se aplica en serio el principio in dubio pro reo siempre que las dudas sobre la posición de garante en el caso concreto sean fundadas, se satisfará el mandato de certeza.

\subsection{Posiciones de garante en virtud de la función de protección de un bien jurídico determinado}

Esta parte del presente artículo será breve y no detallada por el espacio, en procura de lograr la orientación para ser desarrollada en otros trabajos. Отто considera las siguientes relaciones de protección del bien jurídico, para entender la posición del garante en los tipos penales de omisión impropia o comisión por omisión.

\subsection{La posición de garante por vínculo familiar ${ }^{79}$}

Este criterio, se sustenta en las relaciones de familia, donde existe la confianza de la actuación en la protección de los bienes jurídicos. Y cuando las relaciones se mantienen en una convivencia actual.

Отто, Н. ор. cit., p. 259. 
Por eso la exigencia de actuación será esperada y por lo mismo existirá la responsabilidad. En el caso de cónyuges no termina con el divorcio, sino con la separación total. En este contexto, LORENZO MORILlas sostiene que: Debe existir una relación progresiva de hechos que amplía la tradicional comprensión del especifico vínculo familiar hasta llevarla a la idea de dependencia intensa efectiva, que puede no darse en relaciones muy próximas $y$ presentarse, sin embargo, en algunas lejanas. Pero como señala MIR PUIG: Entre más se alejen las relaciones familiares, más precauciones hay que tomar para asumir la comisión por omisión $^{80}$.

Además, este autor incluye un elemento valorativo de la concurrencia de un vínculo afectivo de dependencia absoluta de una persona, con respecto de otra, asumida por parte de ésta, ya que ejemplifica que un niño recién nacido queda en manos del facultativo, y en esta situación muere; no se les puede imputar el homicidio a sus padres, ya que el vínculo estaba en dominio del médico o del personal de atención ${ }^{81}$.

\section{5. 2. Posición de garante por comunidad de riesgo ${ }^{82}$}

Esta se origina cuando los seres humanos se encuentran juntos en una comunidad, según su esencia; se construye en la ayuda y asistencia recíprocas.

SAntiago Mir Puig alude con esta expresión a la participación voluntaria en una actividad peligrosa, en la cual intervienen varias

\footnotetext{
80 Morillas Cuevas, L. op. cit., p. 412.

81 Mir Puig, S. op. cit., pp. 330- 331.

82 Отто, Н. op. cit., p. 262.
} 
personas tácticamente obligadas, en su caso, de socorrerse entre sí (por ejemplo, una expedición alpina). En el caso de que alguno de ellos sufre un accidente relacionado con el riesgo típico de la actividad compartida, se encuentran respecto de él en posición de garante todos los demás ${ }^{83}$.

Morillas Cuevas, sostiene que: Son las que surgen de la confianza especial que deriva en la garantía de la unión de ámbitos de organización, previa a la necesidad, para el auxilio mutuo ${ }^{84}$.

En este orden de ideas, Diego Manuel Luzón-PeÑa aporta con la construcción de esta posición de garante, es una convivencia o comunidad, pero no prolongada. Para algunas personas con profesiones o cargos especiales sí hay deberes jurídicos de garantía, impuestos unas veces por la Ley, como el caso de los bomberos o miembros de unidades militares, que intervienen en caso de incendio, o los miembros de una tripulación de naves y aeronaves frente a los pasajeros en casos de emergencias. Y otras ocasiones se lo hace por contrato, así sucede, por ejemplo, con el guía alpino, quienes en general generan confianza en la actividad $y$ en el momento de una emergencia ${ }^{85}$.

\footnotetext{
83 Отто, Н. op. cit., p. 331.

84 Morillas Cueva, L. op. cit., p. 413; MiR Puig, S. op. cit., p. 331.

85 LuZÓN-PeÑA, D. M. op. cit., p. 602.
} 


\subsubsection{Posición de garante por asunción voluntaria de funciones de protección ${ }^{86}$}

Es cuando la persona asume una función de protección, de la cual se origina un deber de defensa, ante los peligros que amenazan al destinatario de la protección.

Lorenzo Morillos Cuevas ${ }^{87}$ propone que hay tres formas para entender mejor esta construcción de posición de garante y son los siguientes:

Acuerdo directo con el afectado: Es el que confía en la disponibilidad para la intervención del garante, y acepta riesgos o deja de tomar precauciones, que de otra manera los hubiera tomado él (es lo más cercano al contrato); por ejemplo, el enfermero, quien cuida al enfermo en la noche, la niñera, la maestra de preescolar, el guardia de vidas, el guía de montaña, el agente de policía, el médico frente al paciente.

La aceptación genérica: Es aquella que conlleva la obligación de evitar riesgos para determinados bienes jurídicos; por ejemplo, el caso del bañista, cuya misión es la de cuidar o vigilar a los niños y personas, quienes no saben nadar, pero que ante el desfallecimiento de una persona mayor dentro de la piscina, ha de actuar.

86 Отто, Н. op. cit., p. 263.

87 Morillas Cuevas, L. op. cit., p. 413. 
Admisión espontanea y unilateral de la tutela: Una vez comenzada la acción, el sujeto la abandona; por ejemplo, el conductor que se encuentra a un herido en la calzada, lo lleva en su auto y a mitad de camino, decide dejarlo nuevamente en la calle.

Protección voluntaria alternativa: Cuando una persona, quien tiene al cuidado de una persona y la deja en manos de otra: por ejemplo, la madre que tiene que salir de su casa, y deja a su hijo, de tres meses, al cuidado de su vecina.

\subsubsection{Asunción de funciones de protección en el ámbito privado $^{88}$}

Son las que nacen de las relaciones profesionales, por ejemplo, del profesional o de una partera, o en casos individuales, como el de la niñera.

\subsubsection{Posiciones de garante por deberes de servicio o de su cargo ${ }^{89}$}

Es cuando la persona, en razón de sus cargo, tiene la protección de bienes jurídicos, sean estos individuales o supraindividuales, lo cual se sustenta en las relaciones recíprocas.

Se pueden presentar dos situaciones: la protección de bienes jurídicos individuales, cuando las personas se encuentran en la situación de inseguridad, deben proteger a las personas, y éstas

\footnotetext{
88 Отто, Н. p. 263.

89 Ibíd. p. 265.
} 
pueden requerir de esa protección. La excepción se da cuando ella pueda protegerse a sí misma. Y los supraindividuales, cuando se asumen cargos de protección del medio ambiente: del agua, el aire, la tierra. Se tiene el deber y la facultad de defensa, unidos a la asunción voluntaria y efectiva del cargo, el cual genera el deber del titular del cargo.

\subsubsection{Deber de garante por la buena $\mathrm{fe}^{90}$}

Es un deber que la doctrina no acepta, pero es cuando se fundamenta en deberes especiales de información, a partir del principio de buena fe, nacen relaciones de vínculos especiales de confianza. Por ejemplo, en los casos en que los contratantes no tienen una relación de informarse y protegerse recíprocamente. Se da solo en los casos que tengan especiales vínculos de confianza, tales como en el desplazamiento del patrimonio, en los casos de abuso de confianza.

\subsubsection{Traslados de funciones de protección ${ }^{91}$}

En los casos en que alguien ha generado el desamparo de otro o su necesidad de protección, la jurisprudencia admite un deber de garante del autor, con respecto a quien necesita protección frente a afectaciones contrarias a Derecho, por parte de terceros; por ejemplo, el autor expone un caso, cuando a A y K le roban a $\mathrm{C}$, con actos de violencia y los dejan mal heridos. Después de cierto tiempo, regresan y encuentran a $\mathrm{C}$ que gemía, por lo cual $\mathrm{K}$ decide matarlo. En este caso, A debió impedir el acto de K.

\footnotetext{
$90 \quad$ Ibíd. p. 267.

91 Отто, Н. op. cit., p. 268.
} 


\subsubsection{Posiciones de garante en virtud del deber de vigilancia de una fuente de peligro}

\section{a. Posición de garante por el actuar precedente peligroso (injerencia) ${ }^{92}$}

El deber de garante por el actuar precedente es controvertido por principio y en sus supuestos. El actuar precedente tiene que haber sido peligroso, precisamente con relación al resultado producido, de manera tal que haya creado el peligro próximo (adecuado e inmediato) de realización del resultado. El peligro de lesión del bien jurídico tiene que estar establecido en el actuar, de manera que sea de inmediato, objetivamente reconocible.

DonnA, citando a GIMBERnAT, menciona que este autor da un preciso concepto de injerencia:

De acuerdo con este principio, el que mediante un hacer precedente (injerente) crea un peligro de lesión de un bien jurídico, responde de esa lesión, igual que si hubiera causado, mediante una acción positiva, si posteriormente omite evitar el resultado típico en el que va a desembocar la cadena causal, puesta en marcha por aquél para hacer precedente ${ }^{93}$.

Por ejemplo, el posadero $\mathrm{G}$ ha comprado hongos a un comerciante en el mercado, los ha preparado y acaba de servirles a $\mathrm{X}$, cuando se entera de que los hongos son venosos, $\mathrm{G}$ no hace nada y $\mathrm{X}$ muere a causa de la intoxicación por los hongos.

\footnotetext{
92 Ibíd. p. 270.

93 DonNA, E. A. op. cit., p. 282.
} 


\section{b. Posición de garante por el dominio sobre un ámbito de peligro ${ }^{94}$}

Es aquella en cuyo ámbito de dominio se realizan situaciones de hecho o se hallan cosas, a partir de las cuales pueden desarrollarse peligros para los bienes jurídicos de terceros; está obligado a controlar el ámbito de dominio abstractamente peligroso y a impedir, que se concreten los posibles peligros y de ellos surjan perjuicios para los bienes jurídicos ajenos. Por ejemplo, en los casos de tenencia de animales, vehículos, almacenamiento de tóxicos u otros similares, minas, tranvías, etc.

\section{c. Posición de garante por la posesión de un ámbito de dominio jurídicamente protegido ${ }^{95}$}

Este deber se fundamenta en la estrecha relación con la posición de garante por dominio sobre un ámbito de peligro se puede ver la posición de garante por la posesión de un ámbito de dominio (normalmente inocuo). Por ejemplo, es cuando A que es esposo de $\mathrm{B}$, y B es quien practica abortos a mujeres, la jurisprudencia considera que debe imputar responsabilidad A, por no haber impedido los abortos, ya que consideran que el dominio donde se practicaban es un lugar intimo en el cual se desarrolla la esfera intima de la comunidad humana mas reducida, en el que el control estatal solo puede intervenir bajo presupuestos agravados.

Por ejemplo, DonNA, sostiene quienes hace zanjas y después no señalizan, por dicha omisión de la conducta se producen

\footnotetext{
$94 \quad$ Ibíd. p. 275.

95 Donna, E. A. op. cit., p. 276.
} 
colisiones de vehículos. El caso de quien empuja al agua a otro, y luego no lo rescata ${ }^{96}$.

\section{d. Posición de garante en razón de la responsabilidad por actuar de otro ${ }^{97}$}

Esta posición de garante se da cuando un sujeto es responsable por el comportamiento de otros, porque jurídicamente obligado a supervisarlos o controlarlos, de tal manera que no ocasionen daños a terceros. Por ejemplo, el padre por las actuaciones de sus hijos menores, el maestro por sus alumnos en horario escolar, el comandante por la actuación de sus subordinados en horarios de trabajo.

\footnotetext{
$96 \quad$ Ibíd. p. 283.

97 Ibíd. p. 279.
} 


\section{LOS ELEMENTOS DEL TIPO DE OMISIÓN IMPROPIA}

La situación típica o tipo objetivo:

En un primer momento; es la estructura de un delito especial, tomando en cuenta que la posición de garante restringe a las personas que realmente tienen un deber normativo y una relación estrecha con el bien jurídico, que no la puede tener cualquier persona.

Con este criterio normativo de la posición de garante, lo que se consigue es la equivalencia de la persona, quien tiene el deber jurídico de proteger el bien jurídico, o de controlar las fuentes de peligro en contra de ese bien jurídico. Debemos entender que en un primer momento, el tipo penal, con su norma, prohíben realizar la acción; por ello, cuando se refiere a los delitos de comisión, su estructura es de actuar en contra de esa norma y producir un resultado, en ese mismo sentido el tipo de omisión impropia es cuando estando en la posición de garante, no realiza los actos de protección a favor del bien jurídico, teniendo la capacidad de hacerlo para evitar que se produzca ese resultado.

Ese resultado es el que producirá la lesión del bien jurídico, siendo el resultado de carácter material, según los delitos que la norma penal ecuatoriano ha descrito. En este sentido, EDGARDO DonnA admite que pueden ser de cualquier resultado, sea de mera actividad, de actividad de peligro abstracto, concreto o de lesión. MAURACH solo admite los delitos de resultado para los delitos de lesión ${ }^{98}$.

98 DonnA, E. A. op. cit., p. 323 


\section{El tipo subjetivo:}

En este sentido, Donna sostiene que el elemento subjetivo o dolo, es el mismo que en el delito de acción, por cuanto se tiene el conocimiento de la infracción de la norma que tiene el deber de cumplir el mandato, en su condición de sujeto, quien ostenta la relación directa con el bien jurídico y, además, de la confianza de su actuación para evitar el resultado.

Asimismo, tendrá el dominio de su actuación y del conocimiento de los demás elementos del tipo penal.

\section{La autoría, la coautoría}

Es autor, quien tiene la calidad de posición de garante, pero debe tener una relación o vinculación absoluta en el caso en concreto, que no pueda evitar su actuación, ya que si lo hace, producirá el resultado.

No debemos olvidarnos que esa posición de garante, con los criterios materiales o funciones, que son de protección o de control, que hemos revisado en líneas anteriores, no darán la idea de quiénes pueden ser autores. Y es fundamental el dominio sobre el fundamento del resultado, asentado en la lesión, que supone al bien jurídico, y con el sustento de la doble vertiente de desamparo del bien jurídico y el dominio material sobre el foco de peligro, propuesto por BERND SCHÛNEMANN.

En ese sentido, la coautoría también es posible en los delitos impropios de omisión, ésta debe cumplir con los criterios de: 
1. Acuerdo común;

2. Contribución esencial e importancia del aporte;

3. Contribución en la fase de ejecución. Comprende la exteriorización de los actos;

4. Estructura horizontal de los coautores; y,

5. Sentido y contenido del común acuerdo. Por ejemplo, tres personas están de acuerdo con el resto en robar una institución bancaria y en su posición de garantes de protección del bien jurídico omiten las tres sus actos, los cuales tienen la capacidad individual para poder evitarlos, con accionar los botones de seguridad del banco para dar aviso a la Policía; con sus acciones, permiten que se consume el delito.

En relación con la antijuricidad, existe el desvalor de acción cuando esta omisión impropia realiza los elementos del tipo penal y se adecúan en la tipicidad, con lo cual violenta la norma, que ordena que protejan o controlen la fuente de peligro, la cual puede afectar al bien jurídico.

Respecto a la culpabilidad, tiene los mismos elementos, los cuales no difieren en nada con los delitos de acción. 


\section{CONCLUSIONES}

El desarrollo del Derecho penal de acto se ha constituido en una de las garantías para limitar y vincular al poder punitivo, con la finalidad que solo sean castigadas las conductas humanas, que sean peligrosas en juicio ex ante, que puedan llegar a afectar un bien jurídico.

Se ha construido la teoría del delito, encontrando siempre la dualidad de las modalidades de la conducta humana, que son la acción y la omisión, con lo cual se ha querido construir una herramienta útil para poder evitar la expansión del Derecho penal y que solo sean castigadas las que merecen serlo.

La teoría de la imputación siempre se desarrolló con base a la persona, cuya conducta humana es dominada por su voluntad, y que luego fue transformada en teoría de la acción, como su fundamento.

La evolución que ha tenido, tanto la acción como la omisión, en la teoría del delito ha sido desde considerar a éstas como un simple movimiento corporal, que puede causar o puede evitar.

Como en la teoría del delito, se han creado siempre criterios normativos para poder delimitar de mejor manera al poder punitivo, eso sucede con la omisión propia e impropia. Lo importante es qué se hacen en una discusión y para poder conseguir resultados convincentes y coherentes.

Las categorías ontológicas de la realización de una acción u omisión deben complementarse con criterios normativos, que permitan desarrollar de mejor manera esta categoría; es 
importante no dejar la discusión en la simple enunciación de la posición ontológica, sin abordar que existen temas de criterios valorativos en esa misma construcción.

La omisión impropia debe buscar la equivalencia con la acción, lo cual se ha ido construyendo con la posición de garante. Esta categoría no es un criterio fundamental, sino restrictivo, por cuanto solo pueden ser garantes aquéllos que realmente puedan ser reconocidos en cada uno de los casos en concreto.

Los diversos criterios que se encuentran en las fuentes formales, en las materiales o en las mixtas han fortalecido la construcción de esta categoría dogmática desde la fuente formal de la Ley o el contrato y se complementan con los criterios, que tienen relación con el bien jurídico.

Estos dos últimos hacen que se entienda y se delimite de mejor manera la posición de garantía, ya que son los deberes de protección o de control de fuentes de peligro. Con esos aportes, la dogmática penal ha logrado restringir quiénes pueden ser calificados en este delito especial, como quiénes ocupan la posición de garante, en relación con el bien jurídico.

El tema de la causalidad ha logrado ser superado, cuando se determina que no existe en la omisión una causalidad real, sino una causalidad de condiciones mínimas, con los criterios valorativos, que se fijan en cada una de las posiciones de garantes.

Este tema, como todos los temas del Derecho, o de una construcción humana, estarán sujetos a una crítica y se buscará su reformulación; los modelos explicativos no son absolutos, sino relativos y en permanente cambio. 


\section{REFERENCIAS BIBLIOGRÁFICAS}

BACIGAluPO ZAPATER, ENRIQUE. Derecho penal. Parte general. Lima, ARA Editores, 2004.

DONNA, EDGARDO ALBERTO. Derecho penal. Parte general. Tomo VI. Santa Fe, Editorial Rubinzal-Culzoni, 2010.

FERRAJOLI, LUIGI. Derecho y Razón. Valencia, Editorial Trotta, 2001.

LUZÓN-PEÑA, DIEGO MANUEL. Lecciones de Derecho penal. Parte general. Valencia, Editorial Tirant lo Blanch, 2016.

FIANDACA, GIOVANNI, y MUSCO, ENZO. Derecho penal. Parte general. Eiroa, Pablo (traducción del italiano). Santa Fe de Bogotá, Editorial Temis, 2006.

KAUfmann, ARMin. Dogmática de los delitos de omisión. Cuello Contreras, Joaquín, y Serrano González, José Luis (traducción del alemán). Madrid, Editorial Marcial Pons, 2006.

MIR PUIG, SANTIAGO. Derecho penal. Parte general. Buenos Aires, Editorial IB\&F, 2016.

MORILlas CUEVA, LORENZO. Derecho penal. Parte general. Madrid, Editorial Dykinson, 2018. 
OTTO, HARRO. Manual de Derecho penal. Teoría general del Derecho penal. 7. a edición, Béguelin, José R. (traducción del alemán). Barcelona, Editorial Atelier, 2017.

RUEDA MARTÍN, MARÍA ÁNGELES. "La acción y la omisión", en Romeo Casabona, Carlos María, Solá, Esteban, y Boldova, Miguel. (coords.). Derecho penal. Parte general. Introducción teoría jurídica del delito. Granada, Editorial Comares, 2013.

SCHÛNEMANN, BERND. Fundamentos y límites de los delitos de omisión impropia. Cuello Contreras, Joaquín, y Serrano González, José Luis (traducción del alemán). Madrid, Editorial Marcial Pons, 2009.

\section{Normas internacionales}

ORGANIZACIÓN DE ESTADOS AMERICANOS. Convención Americana de Derecho Humanos.

\section{Normas nacionales}

CONSTITUCIÓN POLÍTICA DEL ESTADO. Registro Oficial. 2008.

CÓDIGO ORGÁNICO INTEGRAL PENAL. Registro Oficial. 2014. 